\title{
Control of the biofouling bryozoan, Plumatella repens, using pulsed chlorine treatment
}

\author{
R. C. Mant - G. D. Moggridge • D. C. Aldridge
}

Received: 28 November 2011 / Revised: 9 June 2012/ Accepted: 2 August 2012 / Published online: 3 November 2012

(c) CEERS, IAU 2012

\begin{abstract}
Bryozoans are common biofoulers of underdrain filter nozzles in rapid gravity filters in water treatment works. A potential method for controlling bryozoan biofouling is the use of chlorine in backwash water. Repeatedly exposing bryozoan colonies with chlorine for $20 \mathrm{~min}$ every $24 \mathrm{~h}$ in an experimental setting, to replicate what would occur if the backwash was chlorinated, caused significant reduction in colony growth and size. After 10 days repeated treatment in good conditions for bryozoan propagation, the $\mathrm{EC}_{50}$ (the chlorine concentration required to decrease growth such that treated colonies were half the size of control colonies) was $1.6 \mathrm{ppm}$ (SE 0.3). In suboptimal conditions for propagation, the impact of chlorine was greater. The majority of colonies treated with $1 \mathrm{ppm}$ and above did not grow or even decreased in size over 5 days. However, a chlorine concentration of 5 ppm was necessary, even in sub-optimal conditions, to ensure all colonies decreased in size over 5 days of treatment; this is too high to be acceptable to water companies due to the risk of carcinogenic by-products. Nevertheless, the observed decline in feeding activity of bryozoans exposed to chlorine levels $>1 \mathrm{ppm}$ suggests that repeated backwashing with chlorine may cause colony death over time, especially in sub-optimal conditions. Chlorine backwashes may therefore be an effective long-term control strategy, especially in locations such as rapid gravity filters where it
\end{abstract}

R. C. Mant $(\bowtie) \cdot$ G. D. Moggridge

Department of Chemical Engineering and Biotechnology,

University of Cambridge, Pembroke Street,

Cambridge CB2 3RA, UK

e-mail: rebecca.mant@cantab.net

R. C. Mant - D. C. Aldridge

Department of Zoology, University of Cambridge,

Downing Street, Cambridge CB2 3EJ, UK is suggested that upstream processes are likely to create sub-optimal conditions for bryozoan growth.

Keywords Bryozoan - Control - Rapid gravity filters . Water treatment works

\section{Introduction}

Bryozoan biofouling

Bryozoans are suspension-feeding animals that form colonies attached to natural and artificial surfaces (Ryland 1970; McKinney and Jackson 1989; Wood and Okamura 2005). The basic units of the colonies are zooids, which, in freshwater colonies, are connected by either a gelatinous mass or chitin-coated tubes. Bryozoans, especially the tubular species, may be the most common freshwater biofouler (Wood 2005). They cause a biofouling nuisance in a number of settings including aquaculture (Dubost et al. 1996), prawn farms (Baily-Brock and Hayward 1984), irrigation systems (Wood 2005), power plants (Aprosi 1998), waste water treatment works (Wood and Marsh 1999) and drinking water treatment works (Shrivastava and Rao 1985; Smith et al. 2004; Smith 2005; Smith and Batson 2005). In drinking water treatment works in the UK they have been found growing on the filter nozzles at the bottom of rapid gravity filter beds (RGFs), creating backpressure problems, uneven scour during backwashes, and have contributed to $£ 1.49$ million of refurbishment costs within four water treatment companies (Mant et al. 2011).

Bryozoans can be the only biofouler found growing on the RGF nozzles, but they are often accompanied by both hydroids (e.g., Cordylophora spp.) and sponges. Not all water treatment works (WTWs) with biofouling problems 
have visible bryozoans on their filter nozzles, but their dormant dispersive phase, statoblasts, can be found at the majority of works (Mant et al. 2011). In the UK WTWs these bryozoan statoblasts are most commonly from Plumatella repens (Mant et al. 2011).

\section{Potential control strategies}

Bryozoans, as well as the other fouling organisms, need to be controlled at WTWs to reduce biofouling of RGFs. A variety of control strategies have been tried against bryozoans, but there is little reliable experimental data (Wood 2005). Control options for biofouling in general can be divided into physical and chemical controls (Jenner et al. 1998).

In terms of physical control options, it has been reported that increased water velocity, UV, and sonication (Smith et al. 2004) can reduce bryozoan biofouling, although none stop growth completely and none could easily be applied within an RGF. An alternative physical control strategy is the production of anoxic or food-depleted conditions. Three hours of anoxic conditions usually causes mortality of bryozoan zooids (Wood 2005). Anoxic conditions, created by taking the filter beds off-line, are already used to control chironomids in granular activated carbon filter beds (Olsen et al. 2009) and could be used to control bryozoans in RGFs in the same way. However, neither anoxic conditions nor food depletion are likely to kill the dormant statoblast stage of bryozoans.

The alternative to physical control is chemical control. Bryozoans are more sensitive to heavy metals (copper, zinc, cadmium and chromium) than many other invertebrates and fish (Pardue and Wood 1980). However, heavy metals could not be used within WTWs due to their toxicity to humans (WHO 2011). Chlorine (Shrivastava and Rao 1985; Wood and Marsh 1999) and a commercial cleaning solution Clean In Place (CIP, Veola Water Systems, Australia, Smith et al. 2004) have been reported as potential control solutions for adult colonies. CIP is sold in two forms: caustic and acid. Caustic CIP is of $0.25 \%$ hydrogen peroxide, $0.14 \%$ EDTA sodium salt, $2 \%$ sodium hydroxide, $0.2 \%$ Memclean $\mathrm{C}$ and $97.41 \%$ distilled water. Acid CIP is of $0.1 \%$ sulphuric acid, $0.05 \%$ EDTA sodium salt and $99.85 \%$ distilled water (Smith et al. 2004). However, experimental data on chlorine and both forms of CIP is very limited. In terms of chlorine, both Shrivastava and Rao (1985) and Wood and Marsh (1999) suggest that bryozoans can be prevented by chlorination of $5 \mathrm{mg} / \mathrm{l}$. However, both present no direct experimental data, although Wood and Marsh (1999) state that bryozoans only clogged the filter nozzles of sand filters in a water treatment works in WI, USA, when chlorine levels fell from 7 to $2 \mathrm{mg} / \mathrm{l}$. Wood (2005) also reported that a much lower dose
$(0.3 \mathrm{mg} / \mathrm{l})$ of chlorine, in the form of sodium hypochlorite, if dosed over $24 \mathrm{~h}$ can keep bryozoans under control as a maintenance measure but again no experimental data have been presented. In terms of CIP, Smith et al. (2004) state that no colonies treated with CIP contained living polyps, but that there was well-preserved polypide tissue in many of the samples, including the control; making it unclear as to the difference in death between the treatment and controls and no data are presented.

The statoblast problem

One of the most problematic aspects of bryozoan control is the dormant resistant phase in their lifecycle. In the most common freshwater bryozoan, the Plumatellidae, this dormant phase is a statoblast (Wood and Okamura 2005). The statoblasts are seed-like structures of about 0.4-mm length, which are resistant to control measures (such as the use of chlorine), and many treatments that kill adult colonies will not kill the statoblasts (Wood 2005). If the statoblasts are not killed along with the adult colony, the colonies can re-grow from these statoblasts (Wood 2005). Hence, the control of the statoblasts is an important part of controlling bryozoan biofouling.

Of the chemicals tested, the germination of statoblasts is reduced or stopped by chromic nitrate, ferric nitrate, chloroform, methyl alcohol, silver, mercuric and cupric ions (Mukai 1977). None of these treatments are licensed for use within WTWs due to their toxic effects to humans. It has been proposed that the higher level of resistance of the statoblasts may mean that the best method of control is to wait for them to germinate in the spring and target young colonies (Wood 2005).

As the statoblasts are hard to control, completely eradicating the bryozoans with a single dose is likely to require overly high concentrations of any chemical toxin. Therefore, "maintenance" chemical controls using repeat dosing at lower concentration are a more promising option.

\section{Chlorine backwashing}

A possible maintenance control strategy is the application of chlorine treatments in the RGF backwash water, the water used to clean the RGF beds. Chlorine can be an effective control chemical at low concentration; $0.3 \mathrm{mg} / \mathrm{l}$ of chlorine, in the form of sodium hypochlorite dosed over $24 \mathrm{~h}$, has been reported to keep bryozoans under control as a maintenance measure (Wood 2005). Chlorine also has the additional benefit of reducing the growth of another RGF biofouler, the hydroid Cordylophora spp. (Rajagopal et al. 2002; Folino-Rorem and Indelicato 2005; Mant et al. 2012). If multiple organisms are biofouling a single system, it is more cost effective to control all of the organisms 
at the same time. Using multiple separate control programs for each organism rather than a single control program for all organisms is likely to be significantly more expensive. Additionally, it has long been known that some aquatic sessile organism populations can be regulated by competition for space (Connell 1961). Hence, if multiple organisms are biofouling a single structure and one organism is controlled but not the other, the non-controlled organism may multiply to take over the space vacated by the controlled organism.

Despite these potential advantages of chlorine as a control measure, the impact of pulsed chlorine dosing on freshwater fouling bryozoans has not been reported. Specifically, there are no relevant data on the effect of pulsed low level chlorine dosing, which would be necessary if chlorine were applied to the backwash water of RGFs. Applying regular short-term applications to control biofouling rather than continuous treatments can save money and allow biocide discharge criteria to be met (Venkatesan and Sriyutha Murthy 2009). Chlorine has the potential to form carcinogenic disinfectant by-products (Boorman et al. 1999) whose concentrations are tightly regulated within final (drinking) water (Parsons and Jefferson 2006). In RGFs applying chlorine to the backwash would allow the chlorinated water to not go straight through into the final water. However, intermittent chlorination is not always an effective biofouling control strategy. Zebra mussels can detect chlorine in the water and shut their valves protecting themselves from the chlorine; they can survive pulses of $4 \mathrm{~h}$ chlorination, $4 \mathrm{~h}$ no chlorination by this method (Rajagopal et al. 2003). Bryozoans can rapidly retract their lophophore back into their body and close off their aperture (Ryland 1970), potentially giving them a similar protection to zebra mussels. It is therefore important that the response of bryozoans to pulsed chlorine treatment is examined.

\section{Combined control strategies}

The effectiveness of a control program may be increased if multiple control strategies are applied together (Harrington et al. 1997; Shea et al. 2006; Costa et al. 2008). Specifically, organisms are often less tolerant to chemical toxins if the conditions for growth are sub-optimal. Within WTWs organisms may be food limited. Bryozoans have largely caused a problem at the bottom of RGFs and generally by this stage much of the suspended material within the water will have been removed, by coagulation and clarification processes as well as by the filter bed itself (Parsons and Jefferson 2006). Hence, if the primary processes within a works are working efficiently, then bryozoans may become food limited. Bryozoans in such sub-optimal conditions could therefore be more susceptible to chemical controls.
Experimental objectives

Experiments were carried out, in 2009 and 2010 in Cambridge, UK, to assess the impact of chlorine on the survival and growth of bryozoan colonies using an experimental set-up that simulated the situation that would result if chlorine was dosed in the RGF backwash water. The species of bryozoan chosen for the experiment was Plumatella repens, the most commonly found bryozoan within WTWs (Mant et al. 2011). In order to test the hypothesis that the chlorine might be more effective in controlling bryozoans under conditions that were sub-optimal for their growth, the experiments were replicated under both "good" and "sub-optimal" conditions for bryozoan propagation.

\section{Materials and methods}

Growth and husbandry of the bryozoans

The bryozoans were grown from statoblasts collected from Wing WTWs $\left(52^{\circ} 36^{\prime} 54.36^{\prime \prime} \mathrm{N}, 000^{\circ} 40^{\prime} 27.75^{\prime \prime} \mathrm{W}\right)$. The species used, Plumatella repens, was identified from the growth form of the colonies and morphology of the statoblasts as described by Wood and Okamura (2005). Identification was confirmed by SEMs of some of the unhatched statoblasts (the statoblasts were laterally symmetrical and had nodules or were smooth on the annulus, Fig. 1). The statoblasts were hatched on the underside of $60 \mathrm{~mm}$ petri dishes. The dishes were submerged in a shallow tray of dechlorinated tap water at room temperature. Once the statoblasts had hatched they were transferred into propagation tanks connected to large aquaria containing goldfish to condition the water (Wood and Okamura 2005). The propagation tanks were kept at high room temperature $\left(23^{\circ} \mathrm{C}\right)$ and exposed to a 16-h light, 8-h dark regime using fluorescent strip-lighting.

\section{Recording of colony growth and survival}

At the start of the experiments each dish carried between two- and four-hatched statoblasts, and hence possible future colonies. The colonies never grew so large as to be directly touching a neighbouring colony. During the experiment, the size of the colonies was estimated by recording the number of living zooids. Zooids were identified as living if their lophophore was out and actively feeding or, if the lophophore was retracted, if it responded to a blunt probe (by retracting further).

\section{Chlorine treatment}

Tap water was used as the base for all of the experimental treatments with no chlorine added for the control and 


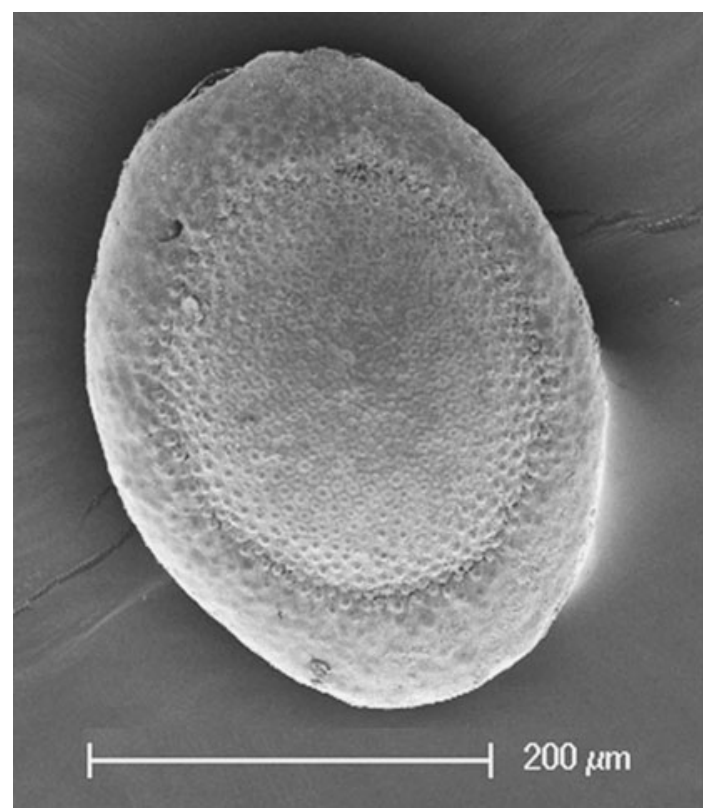

Fig. 1 SEM photograph of one of the unhatched statoblasts used to confirm the species identification

different level of chlorine (in the form of sodium hypochlorite) added for the treatments. River water used in all experiments was collected from the river Cam in Cambridge, UK $\left(52^{\circ} 11^{\prime} 43.50^{\prime \prime} \mathrm{N}, 000^{\circ} 06^{\prime} 53.69^{\prime \prime} \mathrm{E}\right)$, a typical UK lowland watercourse known to contain $P$. repens (D. Aldridge, pers. observ). Data on River Cam water chemistry are given in Table 1.

For the experiments between four and seven bryozoans colonies, attached onto two petri dishes, were transferred to each of six $500 \mathrm{ml}$ plastic "treatment" containers; one container for each chlorine dose of 1, 2, 3, 4 and $5 \mathrm{ppm}$ and one control. The dosing was conducted using a flow-through dosing system. A 251 header tank was connected to the 500-ml treatment container holding the bryozoans. The chlorine dose was added to the header tank and tested at the start of the experiment, using an Oakton C301 Colorimeter. The chlorine concentration, of $1-5 \mathrm{ppm}$, stayed constant

Table 1 Summary of water chemistry parameters for the River Cam (Newnham, Cambridge, $52^{\circ} 11^{\prime} 49.78^{\prime \prime} \mathrm{N}, 000^{\circ} 07^{\prime} 04.53^{\prime \prime} \mathrm{E}$ ) from where experimental river water was collected

\begin{tabular}{llc}
\hline Parameter & Mean & SD \\
\hline Alkalinity $\left(\mathrm{mg} \mathrm{CaCO}_{3} / \mathrm{l}\right)$ & 207.53 & 68.11 \\
Ammonia $(\mathrm{mgN} / \mathrm{l})$ & 0.063 & 0.033 \\
$\mathrm{DO}_{2}(\%$ saturation $)$ & 94.97 & 9.96 \\
Total nitrates $(\mathrm{mg} / \mathrm{l})$ & 39.36 & 1.42 \\
Total phosphates $(\mathrm{mg} / \mathrm{l})$ & 0.85 & 0.18 \\
$\mathrm{pH}$ (range) & $8.07-8.42$ & \\
\hline
\end{tabular}

Data provided by UK Environment Agency. Mean values and ranges are based on data collected between 2006 and 2009 throughout the 20 min dose $( \pm 0.01 \mathrm{ppm})$. The water from the header tank was allowed to flow through the 500-ml treatment container for $20 \mathrm{~min}$ at an average rate of $0.45 \mathrm{l} / \mathrm{min}$. The header tanks were then switched so that river water flowed through the treatment container for a further 6 min. Preliminary trials with dyed water indicated that this was the time it took for a complete water replacement within the container. At the end of the dosing, the petri dishes were taken out of the treatment containers and rinsed in river water. All the treatment dosing was done at room temperature, $20{ }^{\circ} \mathrm{C}$. The colonies were treated for either 10 consecutive days (good conditions experiment) or 5 days (sub-optimal growth conditions experiment).

\section{Good conditions experiment}

To simulate good conditions, in the $24 \mathrm{~h}$ between treatments the dishes were kept together in the propagation tanks. The number of zooids at the start of the experiment was between 2 and 4 per colony (mean 1.8, SD 0.8). There was no significant difference in the starting colony size (i.e. the number of zooids) in the six treatment containers (ANOVA of colony size on day zero against treatment, $F=0.073, d f=1,28, p=0.708)$. In the good condition experiments there were five colonies in the control, 2, 3 and $5 \mathrm{ppm}$ treatments, four colonies in the $1 \mathrm{ppm}$ treatment and six colonies in the 4 ppm treatment.

\section{Sub-optimal conditions experiment}

To simulate sub-optimal conditions, rather than being transferred back to the propagation tanks after dosing, the colonies were kept in a single 10-1 container of river water [collected from the river Cam, at Cambridge, UK $\left(52^{\circ} 11^{\prime} 43.50^{\prime \prime} \mathrm{N}\right.$, $\left.\left.000^{\circ} 06^{\prime} 53.69^{\prime \prime} \mathrm{E}\right)\right]$. The water within the container was replaced every $24 \mathrm{~h}$ but otherwise there was no replenishment of food, and the containers were not aerated. The average number of zooids per colony, 14.8 (SD 5.3), at the start of the experiment was greater than for the good conditions experiment (varying from 5 to 25 zooids per colony). Despite the range of colony sizes, as with the good conditions experiment, there was no significant difference in starting colony size between the six treatment groups (average per treatment varied from 13.0 to 16.7; ANOVA of colony size on day zero against treatment, $F=0.949, d f=1,38, p=0.336$ ). In the sub-optimal conditions experiment there were six colonies in the 3 and 4 ppm treatments and seven colonies in the control, 1,2 and 5 ppm treatments.

Statistical analysis

The number of living zooids present was recorded for each colony each day just before the next treatment dose was 
applied (i.e. $24 \mathrm{~h}$ after the previous treatment dose). The data were analysed using the statistical program $\mathrm{R}$ version 2.9.1 (The $\mathrm{R}$ Foundation for Statistical Computing, 2009-06-26). Log-log dose-response curves were fitted to the growth rates using an $\mathrm{R}$ package designed to fit doseresponse curves called 'drc' (Ritz and Streibig 2005) and corresponding $\mathrm{EC}_{50} \mathrm{~s}$ were calculated (the effective concentration required to reduce the growth rate by $50 \%$ ). General linear models of the initial dose-response relationship were fitted using the package 'Ime' (R package version 3.1-92).

\section{Results and discussion}

Relative resistance of bryozoans to chlorine: single dose in good and stressed conditions

Bryozoans were relatively resistant to chlorine: a single 20-min dose of chlorine, of up to $5 \mathrm{ppm}$, did not affect bryozoan colonies sufficiently to cause significant zooid death either in the 'good' or 'sub-optimal' conditions. In good conditions, a single dose of chlorine had no apparent impact on bryozoan survival (Fig. 2). There was no reduction in colony size and most colonies showed evidence of growth in the $24 \mathrm{~h}$ after dosing. Moreover, there was no suggestion of a dose-response effect. There was no significant relationship between the size of a bryozoan colony and the chlorine dose $24 \mathrm{~h}$ after a single $20 \mathrm{~min}$ dose (linear model of size of the colonies as a proportion of the original colony after $24 \mathrm{~h}$ by dose, $F=2.900$, $d f=1,28, p=0.100$ ) (Fig. 3). However, it was observed that the chlorine dosing did cause the lophophores to retract and stop feeding.

Chlorine resistance in bryozoans may partially be due to this ability to rapidly retract their lophophore back into their body and close off their aperture (Ryland 1970). The walls of the zooids are chitinized, and a variety of organic and inorganic particles adhere to them (Wood and Okamura 2005). Chlorine dose not penetrate well through biofilms (Debeer et al. 1994), and hence the tube walls likely protected the zooids against intermittent dosing of chlorine. When the lophophores are retracted, less of the colony is exposed. Zebra mussels show similar resistance to chlorine; they close their valves when they detect chlorine in the water and thereby achieve resistance to intermittent dosing (Rajagopal, et al. 2003).

In sub-optimal conditions, a single dose of chlorine still had little impact (Fig. 3). Again, the majority of colonies had increased in size for all treatments and there was no suggestion of a dose-response effect. There was no significant relationship between the size of a bryozoan colony and chlorine dose $24 \mathrm{~h}$ after a single 20-min dose (linear

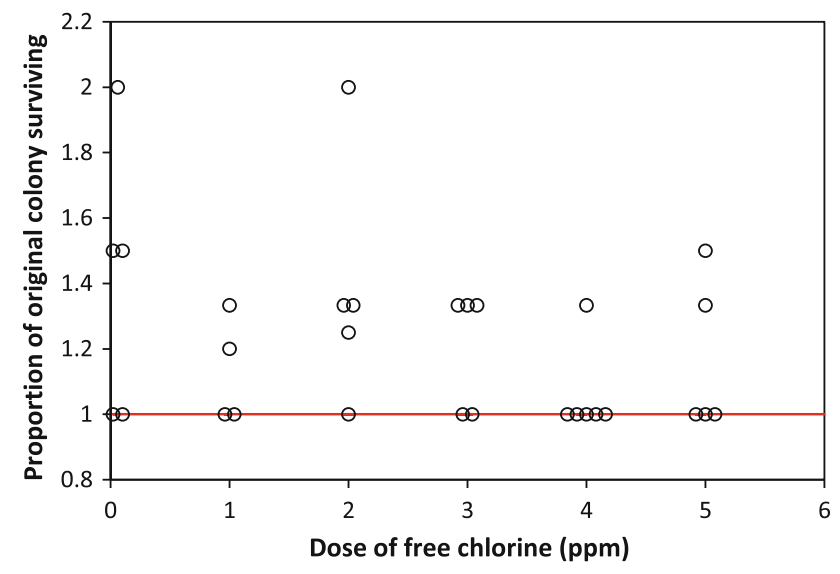

Fig. 2 The size of the Plumatella repens colonies (as a proportion of the original colony) $24 \mathrm{~h}$ after a single 20 -min dose of chlorine in good conditions; Each circle represents a single colony; the circles have been offset from their exact dose so as to make all colonies visible (points above the line indicate growth and points below the line death)

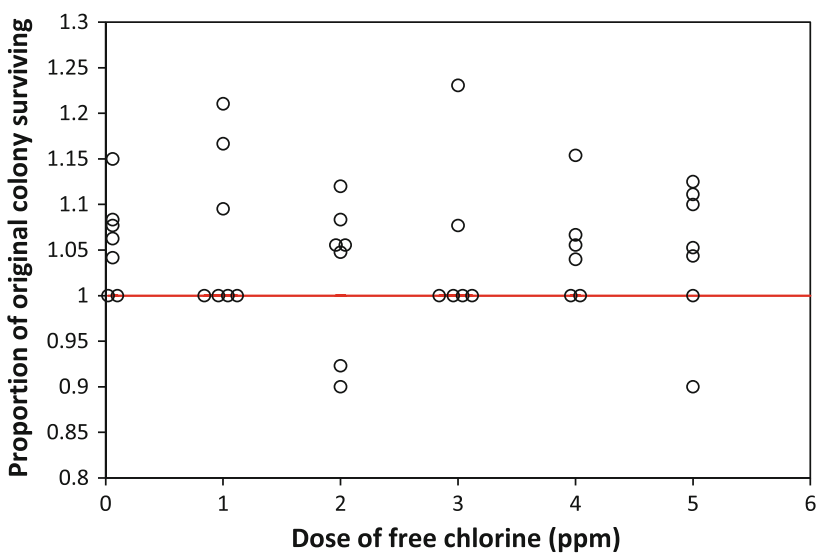

Fig. 3 The size of the Plumatella repens colonies (as a proportion of the original colony) $24 \mathrm{~h}$ after a single 20 -min dose of chlorine in suboptimal conditions. Each circle represents a single colony; the circles have been offset from their exact dose so as to make all colonies visible (points above the line indicate growth and points below the line death)

model of size of the colony (as a proportion of the starting colony) after 24 h against dose $F=0.116, d f=1,38$, $p=0.736)$.

Effect of repeat chlorine dosing

With repeated daily doses over 10 days a significant difference in colony size between different treatments became apparent even in good conditions (Fig. 4). The 4- and 5 -ppm dosed colonies remained at roughly their original size throughout the 10-day treatment, whereas the control, 1- and 2-ppm treatments grew throughout the 10 days of treatment. The 3-ppm dosed colonies grew in the first 3 days after which colony size on average remained 


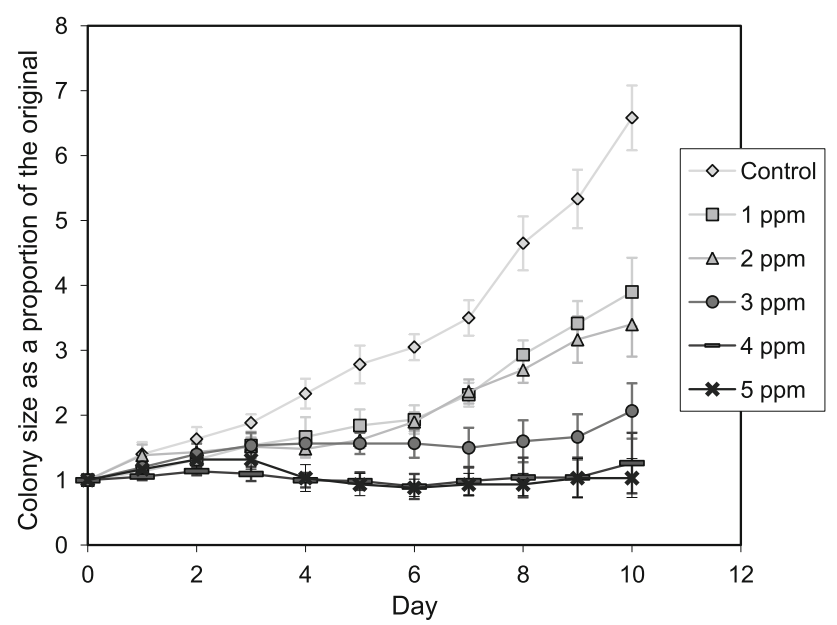

Fig. 4 The effect of repeated chlorine dosing in good conditions on Plumatella repens; Change in colony size (as a proportion of the original colony) with repeated daily dosing. Error bars show the standard error, $n$ varies between 4 and 6 for the different doses (see "Materials and methods")

unchanged (the average slope, change in colony size, was not significantly different from zero; one sample $t$ test on the slope of regression lines fitted to colony each $t=1.60$, $d f=4, p=0.18$ ).

The dose-response relationship can be seen more clearly by fitting a dose-response curve to the size of the colonies after 10 days (as a proportion of the starting colony size) for each colony against dose (a proportion of greater than one indicates increase in zooid number and less that one indicates decrease in zooid number) (Fig. 5). The $\mathrm{EC}_{50}$ for the fitted curve was 1.62 (SE 0.34). Hence, a daily 20-min dose of $1.6 \mathrm{ppm}$ chlorine reduced the growth of the colonies such that after 10 days the colonies were half the size of the control colonies. After 10 days repeated treatment, colonies dosed at $5 \mathrm{ppm}$ were on average about four times smaller than those dosed at $1 \mathrm{ppm}$. Some of the 4- and 5-ppm dosed colonies had even decreased in size (average growth rate was negative). However, even with $5 \mathrm{ppm}$ some colonies had still grown over the 10-day period.

Overall, despite the bryozoans being able to retract their lophophore, the chlorine still had a sub-lethal impact on them, reducing their growth rate even in good conditions. The bryozoan tube walls are unlikely to be completely impermeable to chlorine and hence it could cause some damage. The end of the lophophore near the entrance to the tube would be least protected and damage to the lophophore is likely to affect feeding ability. The lophophores, however, did not show clear signs of physical damage and further investigation would be needed to fully understand the impact of chlorine on the ciliary feeding mechanisms. The retraction of the lophophore in the presence of chlorine will stop the bryozoans feeding during the dosing and may

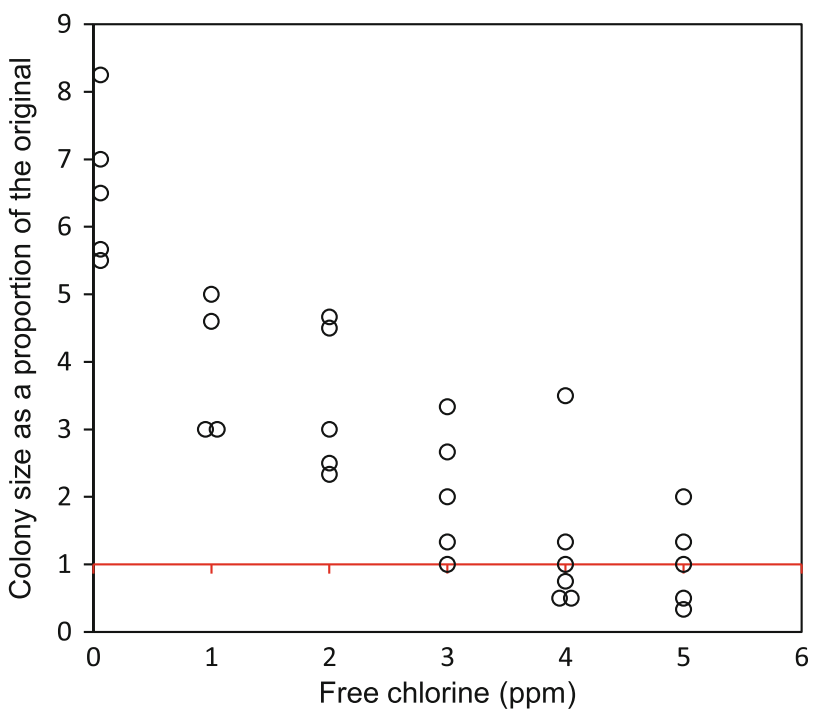

Fig. 5 The effect of repeated chlorine dosing in good conditions on Plumatella repens; The size of the colonies (as a proportion of the original colony) after 10 days dosing against dose. Each circle represents a single colony, where colonies overlapped the circles have been offset from the exact dose so as to make all colonies visible. (Points above the line indicate growth and points below the line death)

inhibit the protrusion of the lophophore even after the end of the treatment, a larger proportion of zooids had their lophophores retracted when trying to count the colonies treated with high-chlorine concentrations although this was not quantified. Future research should include greater examination of the lophophore activity in colonies treated with chlorine.

With the higher chlorine doses, some zooids died within the colonies (although there was also some production of new zooids). The zooids that died did not die suddenly but appeared to slowly decrease in size and get weaker before death. Figure 6 shows the physical appearance of the colonies after 10 days treatment with different concentrations of chlorine. In the 4- and 5-ppm treatments many of the zooids that were present and alive had qualitatively appeared to have shrunk in size and looked smaller than those in the other treatments, although this was not quantitatively measured. This may suggest that the bryozoans were starving, consistent with the hypothesis that the chlorine was reducing their feeding abilities. However, the feeding rates of the colonies were not recorded, to avoid extra disturbance to the colonies during the experiments, however, this limits our ability to accurately assess the impact of the chlorine on feeding. Future experiments should count the faecal pellets produced with and without chlorine treatment. If chlorine is affecting the colonies through reducing their feeding, then continued dosing may have a larger impact especially on the 3-ppm (and above) 


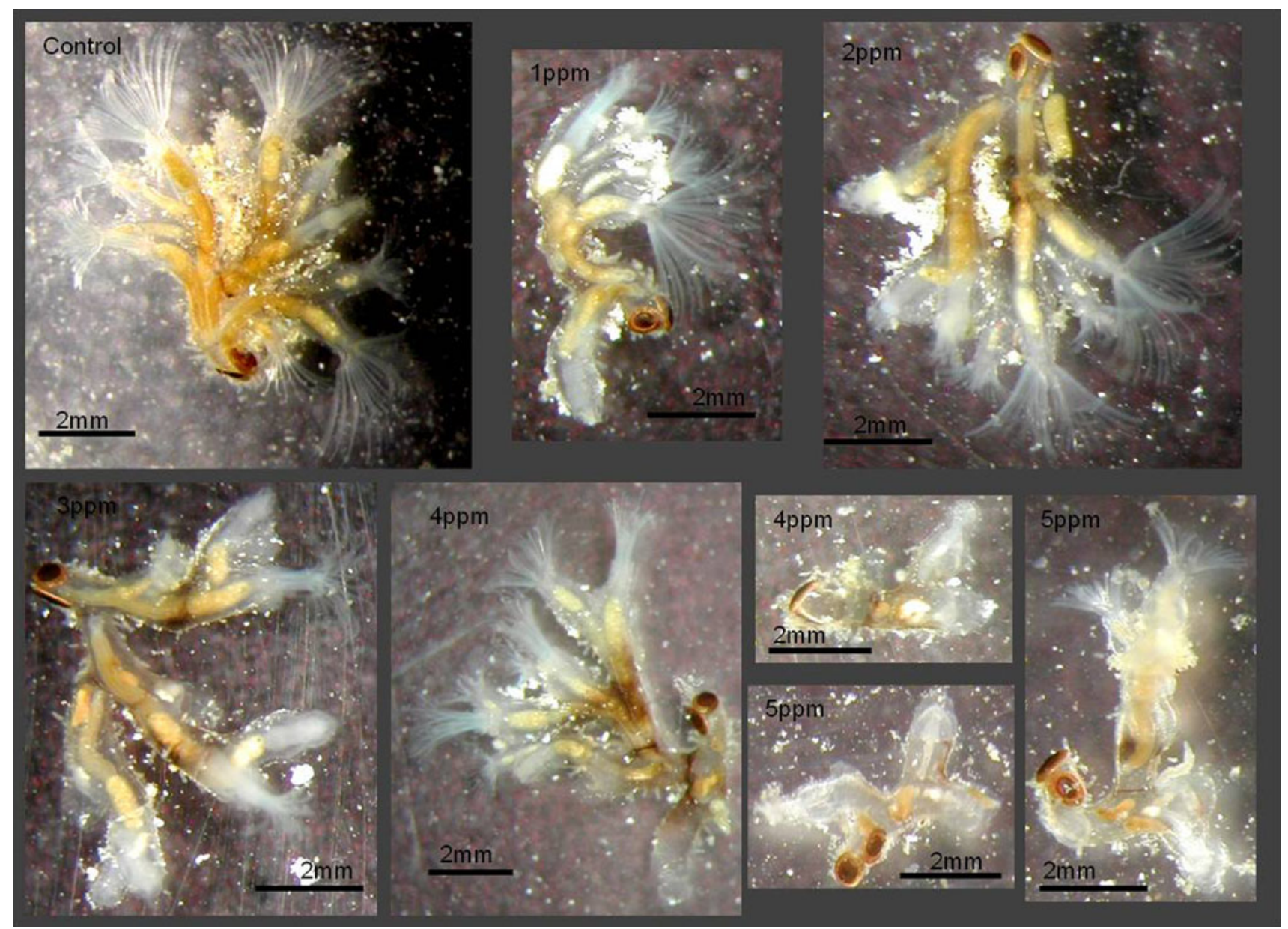

Fig. 6 Photographs of Plumatella repens colonies treated with chlorine for 20 min every day for 10 days in good conditions. The dose the colony received is labelled in the top left corner of each of the photos

dosed colonies which did not grow significantly during the 10 days of treatment in good conditions.

\section{Effect of sub-optimal conditions}

Figure 7 shows that in sub-optimal conditions there is little growth even in the unexposed control colonies. However, there is still a strong dose-response relationship which becomes increasingly apparent after day 3 when repeat chlorine dosing at higher doses not only inhibits growth but also causes the death of zooids.

Figure 8 shows directly the size of the colonies after 5 days of repeated chlorine control in sub-optimal conditions. There was a significant negative relationship between size of the colonies and dose (linear model of growth rate against dose $F=14.791, d f=1,38, p=0.0004)$. In other words, in sub-optimal conditions there was not only the retardation of growth seen in good conditions but also

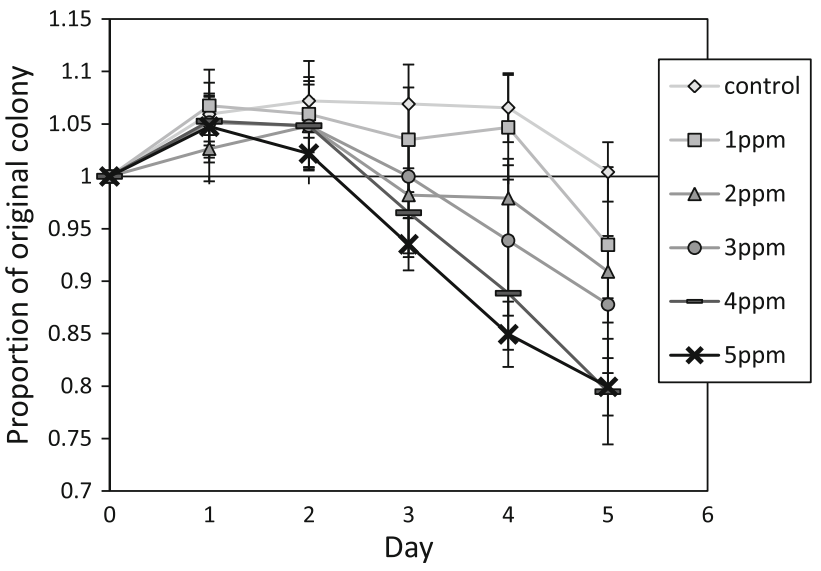

Fig. 7 The effect of repeated doses in stressed conditions on Plumatella repens; change in colony size (as a proportion of the original colony) with repeated daily dosing. Error bars show the standard error, $n$ varies between 6 and 7 for the different doses (see "Materials and methods") 


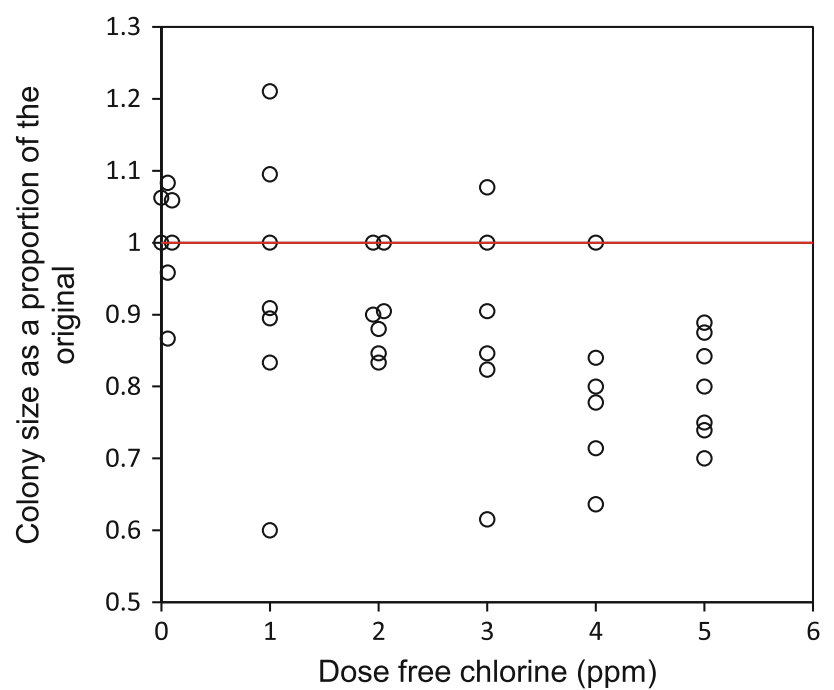

Fig. 8 The effect of repeated doses in stressed conditions on Plumatella repens; The size of the colonies (as a proportion of the original colony) after 10 days dosing against dose. Each circle represents a single colony, where colonies overlapped the circles have been offset from the exact dose so as to make all colonies visible. (Points above the line indicate growth and points below the line death)

zooid death within the colonies and significant decrease in colony size. However, even in sub-optimal conditions it was only with $5 \mathrm{ppm}$ doses that all colonies had decreased in size after 5 days (i.e. had a proportion of original colony size of less than one). Also, the EC-50 (calculated from fitting a $\log -\log$ dose-response curve) is not significantly different from that for good conditions, and the value is actually higher; $2.1 \mathrm{ppm}$ (SE 0.9) compared to $1.6 \mathrm{ppm}$ (SE 0.3).

The impact of chlorine dosing within WTWs will be greater if the bryozoans are in sub-optimal conditions. Bryozoans largely feed on nanoplankton (Ryland 1970), and at the bottom of filter beds, where most biofouling problems occur (Mant et al. 2011), the nanoplankton content of the water will have been greatly reduced (Parsons and Jefferson 2006). Rapid gravity filters are often the last main stage for removing solids from the drinking water and the recent designs aim to lower turbidity to below $0.1 \mathrm{NTU}$ (Ratnayaka, et al. 2009). There is no simple conversion of turbidity to suspended solids as it depends on the nature and reflectivity of the suspended solids but this level will be significant reduction to the inflowing river water onto the treatment plants. It is also a challenge to assess at what concentration of particles would be required for optimum bryozoan growth. Plumatella abundances correlate with the nutrient richness, and thus presumably food availability, of river sites (Hartikainen et al. 2009). Hence, even within the natural variability of rivers, Plumatella abundance can be reduced by food availability. It was our intention (although we made the error of not experimentally confirming) that our sub-optimal conditions limited food availability. However, in the sub-optimal conditions of the experiments described here, even a number of the controls started to reduce in size, suggesting that the experimental conditions may have been more stressful than those which occur in the RGFs, where bryozoans grow well enough to cause a biofouling problem. Assessing the condition of bryozoans at the bottom of RGFs would not be easy, as accessing the bottom of RGFs is not possible while the beds are in operation.

\section{Replication and experimental error}

The observations were made on six different sets of bryozoans each exposed to one of five different concentrations of chlorine or a no chlorine control. The bryozoans were not all grown on different petri dishes; however, they were never large enough to touch and hence directly interact. All the bryozoans were hatched from one set of collected statoblasts as we were unable to identify more than one available source. It is possible that statoblasts collected from different areas may have slightly different responses to chlorine if different genotypes and phenotypes are present.

The main statistical analysis was carried out by general linear models to investigate the relationship between chlorine exposure and bryozoan response. The different colonies can be considered as independent replicates for this analysis, providing evidence about the variability in bryozoan response to different levels of chlorine. The potential experimental error in applying the individual chlorine dose is estimated by the deviation from the doseresponse curve derived from the data. The lack of any evidence of such deviation suggests that imprecision in measuring and applying the chlorine dose was not an important source of error. The colonies in the optimal and sub-optimal conditions were different sizes at the start of the experiments, potentially causing differences in the results between the two treatments. Larger colonies, that could potentially have been more resistant due to their large size, were used in the sub-optimal conditions experiments suggesting that the difference in chlorine tolerance between conditions may be greater than observed.

Practical implications

The impact of chlorine treatment within WTWs will depend on the species of bryozoans present. The experiments were conducted on the species most commonly found within UK WTWs, Plumatella repens (Mant et al. 2011). However, there are multiple species of bryozoan present within the UK (Wood and Okamura 2005) and the 
different species may react differently to chlorine doses. The majority of UK freshwater bryozoans belong to the class Phylactolaemata, but there are also two species that belong to the mainly marine class Gymnolaemata (Wood and Okamura 2005), and one of these, Paludicella articulata, has been found in UK WTWs (Mant et al. 2011). It is reasonable to expect that all tubular Plumatellas should react in a similar way, since they are closely related and have a similar body structure. However, the more distantly related $P$. articulata may potentially react differently to the chlorine treatment.

Wood (2005) did not report what bryozoan species he was working with but suggested that a chlorine level as low as $0.3 \mathrm{ppm}$ applied continuously over $24 \mathrm{~h}$ can be used as an effective maintenance treatment. In contrast, our experiments suggest that for a pulsed treatment, a 10 times greater concentration of $3 \mathrm{ppm}$ over a number of days is necessary to prevent growth in good conditions. However, if the RGFs in treatment works are at least partly suboptimal environments for bryozoans, then 5 days of pulsed dosing at $1 \mathrm{ppm}$ may be sufficient to prevent growth. Although a higher chlorine dose than $1 \mathrm{ppm}$ was necessary to produce colony death even in the sub-optimal conditions, if the hypothesis is correct that chlorine affects bryozoans mainly by preventing feeding and promoting starvation, then repeated dosing at low concentrations over a prolonged time period might well be effective. Proving this conclusively requires further research.

Within WTWs, the reaction of chlorine with organic matter to produce carcinogenic by-products (Boorman et al. 1999) precludes any form of high dosing of chlorine before the RGFs, and even lower concentrations dosing continuously. For example, regulations limit trihalomethanes (THMs) produced by chlorination to $<80 \mu \mathrm{g} / \mathrm{l}$ total trihalomethanes (THMs) in the US and $<100 \mu \mathrm{g} / \mathrm{l}$ in the UK (Parsons and Jefferson, 2006). However, chlorinated backwashes are already used within some works because of the works layout (i.e. if chlorinated final, clean, water is used for backwashing) and water companies are willing to apply up to $2 \mathrm{ppm}$ chlorine to the backwash water (B. Holden, Anglian Water, personal communication). At $2 \mathrm{ppm}$ in good conditions, despite this being greater than the $\mathrm{EC}_{50}$, the average colony still more than tripled in size over the 10 days of the experiment and this level of growth could therefore cause a biofouling problem. However, if the water in RGFs is sufficiently nutrient depleted then a low level chlorinated backwash may at least be sufficient to slow the growth of the bryozoans and decrease the regularity with which other treatment options need to be applied. In addition, maintaining the effectiveness of upstream processes could limit food availability and should maximise the effectiveness of the chlorinated backwashes.
A particular appeal of the use of chlorine to control bryozoans in WTWs is that the same product also has the potential to simultaneously control fouling by the hydroid Cordylophora spp.; a single 105-min doses of $4 \mathrm{ppm}$ chlorine can reduce the size of Cordylophora colonies and continuous dosing of $0.1 \mathrm{ppm}$ chlorine can reduce growth (Folino-Rorem and Indelicato 2005 and Rajagopal et al. 2002, respectively). However, in the majority of treatment works where bryozoan fouling is a problem, perhaps particularly where upstream processes are working inefficiently and enable relatively high concentrations of food to reach downstream locations, chlorinated backwashes alone may not be an effective control against all the RGF biofouling present. Other control strategies therefore also need to be considered. A potential alternative control which deserves exploration is the periodic creation of anoxic conditions (Wood 2005). Anoxic conditions are used within granular activated carbon filters to control small invertebrates including chironomid larvae (Olsen et al. 2009) so may be applicable for bryozoans within filter beds. An additional emerging technology is the use of microencapsulated active ingredients (BioBullets) which are targeted at filter feeding biofoulers. Such technology has proven successful in controlling biofouling zebra mussels (Aldridge et al. 2006).

\section{Conclusion}

Bryozoans are relatively resistant to chlorine, with a single 20-min application of up to $5 \mathrm{ppm}$ not causing any zooid death within colonies. Despite this, chlorine can reduce the growth rate of bryozoans and, over time, cause death in sub-optimal conditions. Thus, chlorinated backwashes may help to control bryozoan biofouling. The effectiveness will depend on how well upstream processes are working and how sub-optimal the conditions for bryozoan growth actually are at each location. If the situation in RGFs is adequately characterised by the sub-optimal conditions we created experimentally, then a low level chlorinated backwash may be sufficient to slow, or even stop, the growth of the bryozoans and decrease the regularity with which other treatment options need to be applied. Field trials of chlorinated backwashes are now important to test these hypotheses and to provide pragmatic evidence of the impact of chlorine dosing on in situ bryozoan colonies.

Acknowledgments This work was generously supported by Anglian, Thames, Yorkshire and Severn Trent Waters. Particular thanks goes to Barrie Holden, Michael Chipps, Jenny Banks, Stuart Crymble and Helen Pickett who provided access to sites and gave helpful discussion. 


\section{References}

Aldridge DC, Moggridge GD, Elliott P (2006) Microencapsulated 'BioBullets' for the control of biofouling zebra mussels. Environ Sci Tech 40:975-979

Aprosi G (1998) Bryozoans in the cooling water circuits of a power plant. Proc Int Assoc Theor Appl Limnol 23:1542-1547

Baily-Brock JH, Hayward PJ (1984) A freshwater bryozoan, Hyalinella vaihiriae Hastings (1929), from Hawaiian prawn ponds. Pac Sci 38:199-204

Boorman GA, Dellarco V, Dunnick JK, Chapin RE, Hunter S, Hauchman F, Gardner H, Cox M, Sills RC (1999) Drinking water disinfection byproducts: review and approach to toxicity evaluation. Environ Health Perspect 107:207-217

Connell JH (1961) The influence of interspecific competition and other factors on the distribution of the barnacle Chthamalus stellatus. Ecol. 42:710-723

Costa R, Elliott P, Saraiva PM, Aldridge D, Moggridge GD (2008) Development of sustainable solutions for zebra mussel control through chemical product engineering. Chin J Chem Eng 16:435-440

Debeer D, Srinivasan R, Stewart PS (1994) Direct measurement of chlorine penetration into biofilms during disinfection. Appl Environ Microbiol 60:4339-4344

Dubost N, Masson G, Moreteau JC (1996) Temperate freshwater fouling on floating net cages: method of evaluation, model and composition. Aquaculture 143:303-318

Folino-Rorem NC, Indelicato J (2005) Controlling biofouling caused by the colonial hydroid Cordylophora caspia. Water Res 39:2731-2737

Harrington DK, VanBenschoten JE, Jensen JN, Lewis DP, Neuhauser EF (1997) Combined use of heat and oxidants for controlling adult zebra mussels. Water Res 31:2783-2791

Hartikainen H, Johnes P, Moncrieff C, Okamura B (2009) Bryozoan populations reflect nutrient enrichment and productivity gradients in rivers. Freshwater Biol 54:2320-2334

Jenner HA, Whitehouse JW, Taylor CJL, Khalanski M (1998) Cooling water management in European power stationsbiology and control of fouling. Hydroécologie Appl 10:1-225

Mant RC, Moggridge G, Aldridge DC (2011) Biofouling by Bryozoans, Cordylophora and sponges in UK water treatment works. Water Sci Technol 63:1815-1822

Mant RC, Moggridge GD, Aldridge DC (2012) Control of biofouling by Cordylophora caspia in freshwater using one-off, pulsed and intermittent dosing of chlorine: laboratory evaluation. Biofouling 28:433-440

McKinney FK, Jackson JBC (1989) Bryozoan evolution. Unwin Hyman, Boston

Mukai H (1977) Effects of chemical pretreatment on the germination of statoblasts of the freshwater bryozoan, Pectinatella gelatinosa. Biol Zent 96:19-31

Olsen A, Leadbeater BSC, Callow ME, Holden JB, Bale JS (2009) The origin and population dynamics of annually re-occurring Paratanytarsus grimmii (Diptera: Chironomidae) colonising granular activated carbon (GAC) adsorbers used in potable water treatment. Bull Entomol Res 99:643-651

Pardue WJ, Wood TS (1980) Baseline toxicity data from fresh water bryozoa exposed to copper, cadmium, chromium and zinc. J Tenn Acad Sci 55:27-31

Parsons SA, Jefferson B (2006) Introduction to potable water treatment processes. Blackwell Publishing, Oxford

Rajagopal S, van der Velde G, van der Gaag M, Jenner HA (2002) Laboratory evaluation of the toxicity of chlorine to the fouling hydroid Cordylophora caspia. Biofouling 18:57-64

Rajagopal S, Van der Velde G, Van der Gaag M, Jenner HA (2003) How effective is intermittent chlorination to control adult mussel fouling in cooling water systems? Water Res 37:329-338

Ratnayaka DD, Brandt MJ, Johnson KM (2009) Water Supply, Butterworth-Heinemann, Oxford

Ritz C, Streibig JC (2005) Bioassay analysis using R. J Stat Softw 12(5): $1-22$

Ryland JS (1970) Bryozoans. Hutchinson, London

Shea K, Sheppard A, Woodburn T (2006) Seasonal life-history models for the integrated management of the invasive weed nodding thistle Carduus nutans in Australia. J Appl Ecol 43:517-526

Shrivastava P, Rao KS (1985) Ecology of Plumatella emarginata (Ectoprocta, Phylactolaemata) in the surface waters of MadhyaPradesh with a note on its occurrence in the protected waterworks of Bhopal (India). Environ Pollut Ser A Ecol Biol 39:123-130

Smith AM (2005) Growth and development of biofouling freshwater bryozoans, Southern Reservoir, Dunedin, New Zealand, November 2000 to June 2004, Denisia 16, zugleich Kat. der OO. Landesmuseen. Neue Ser 28:209-222

Smith AMB, Batson PB (2005) Tracking down biofoulers: a survey of freshwater bryozoans around Dunedin, New Zealand. Denisia 16, zugleich Kat. der OO. Landesmuseen. Neue Ser 28:223-230

Smith AM, Brunton MA, Batson PB (2004) Infestation of a temperate reservoir by freshwater bryozoans: an integrated research programme, In: Moyano G, Cancino HI, Jackson JMW (eds) International Bryozoology Association-13th conference. Balkema Publishers, Leiden

Venkatesan R, Sriyutha Murthy P (2009) Macrofouling control in power plants. In: Marine and industrial biofouling. Springer, pp 265-291. ISBN: 978-3-540-69794-7

Wood TS (2005) The pipeline menace of freshwater bryozoans. Denisia 16, zugleich Kat. der OO. Landesmuseen. Neue Ser 28:203-208

Wood TS, Marsh TG (1999) Biofouling of wastewater treatment plants by the freshwater bryozoan, Plumatella vaihiriae (Hastings, 1929). Water Res 33:609-614

Wood TS, Okamura B (2005) A new key to the freshwater bryozoans of Britain, Ireland and continental Europe, with notes on their ecology. Freshwater Biological Association, Ambleside

World Health Organisation (WHO) (2011) Guidelines for drinkingwater quality, 4th edn. World Health Organisation, Publishers 